\title{
Estimativa da erosão em carreadores de cana-de-açúcar através da Equação Universal de Perdas de Solo
}

\author{
Estimation of erosion in earth roads of \\ sugar cane using Universal Soil Loss Equation
}

Gustavo D’Almeida Scarpinella** (), Renato Billia de Miranda² (D), Frederico Fábio Mauad²

\begin{abstract}
RESUMO
A erosão do solo em carreadores de cana-de-açúcar é um problema que não pode ser desprezado, dado o aumento de área plantada com essa cultura no território brasileiro. No presente artigo, são estimadas as perdas de solo, através do emprego da Equação Universal de Perdas de Solo (EUPS), de quatro trechos de carreadores de cana de uma fazenda no município de Itirapina (SP). Os resultados mostraram estimativas de perdas que variaram de 60,6 a 90,1 tha'-1 para o tipo de solo Neossolo Quartzarênico.
\end{abstract}

Palavras-chave: erosão; Equação Universal de Perdas de Solo; carreadores; cana-de-açúcar

\begin{abstract}
Soil erosion in earth roads of sugar cane is a problem that cannot be ignored, given the increase in planted area to this crop in Brazil. In this article soil losses are estimated using the Universal Soil Loss Equation (USLE), at four stretches of sugar cane earth roads of a farm at Itirapina (São Paulo State). Results showed that loss estimates ranged from 60.6 to 90.1 t.ha' ${ }^{-1}$ for typic Quartzipsamment soil.
\end{abstract}

Keywords: erosion; Universal Soil Loss Equation; earth roads; sugar cane.

Embora o Brasil ocupe uma posição importante na publicação de artigos sobre a erosão e conservação dos solos $-12^{\circ}$ lugar no mundo (BARRETO; LINO; SPAROVEK, 2009) —, e as pesquisas nessa área já venham sendo desenvolvidas há aproximadamente 70 anos, relatos ou publicações acadêmicas de análise quantitativa ou qualitativa da produção de sedimentos em carreadores de cana-de-açúcar são raros.

Galeti (1987) afirma que as estradas e os carreadores são pontos vitais no desenvolvimento das atividades dentro de uma propriedade agrícola, pois seu papel é garantir a fácil movimentação entre quaisquer pontos e em qualquer época do ano.

De acordo com Lombardi Neto e Drugowich (1994b), "a construção de estradas pelo simples fato de eliminar a cobertura vegetal e impermeabilizar o solo, seja pela compactação, seja pela cobertura asfáltica, constitui um forte fator predisponente à erosão". Segundo Lombardi Neto \& Drugowich (1994a), os problemas mais graves de erosão podem ser ocasionados pela má localização de estradas e carreadores, os quais 
podem acumular grandes volumes de enxurrada e provocar estragos consideráveis em poucos eventos chuvosos.

Expressa em volume (ou peso) de material erodido por unidade de área por unidade de tempo, a taxa de perda de solo (ou taxa de erosão) é aquela "para a qual o solo é erodido a partir de uma dada área" (FENDRICH et al., 1997).

\section{Equação Universal de Perdas de Solo}

A Equação Universal de Perdas de Solo (EUPS) (Universal Soil Loss Equation - USLE) foi desenvolvida por Wischmeier \& Smith (1978) e depois aprimorada em seus parâmetros por outros pesquisadores. Trata-se de uma equação de regressão múltipla, paramétrica, que prediz a quantidade de solo erodido em uma determinada área de encosta homogênea utilizando parâmetros que "consideram a energia da chuva, a resistência do solo, o deflúvio superficial através da inclinação do terreno e práticas de cultura e de conservação do solo" (RIGHETTO, 1998). Essa equação estima a erosão por sulcos, além da laminar, mas não considera a deposição de sedimentos (AMORIM; SILVA; PRUSKI, 2009). A EUPS é "calculada para um ano ou um tempo definido" (BERTONI \& LOMBARDI NETO, 1985 apud CARVALHO, 2008) e representada através da Equação 1.

$A=R \times K \times L \times S \times C \times P$

Em que:

$A=$ perda de solo por unidade de área e tempo, em t.ha ${ }^{-1} \cdot$ ano $^{-1}-$ valor final da equação;

$R=$ fator de erosividade da chuva, em MJ.ha ${ }^{-1} \cdot \mathrm{mm} \cdot \mathrm{ha}^{-1}$;

$K=$ fator de erodibilidade do solo, em MJ.ha' ${ }^{-1} \cdot \mathrm{mm} \cdot \mathrm{ha}^{-1}$;

$L S=$ fatores topográficos que expressam o comprimento (em metros) e a declividade do terreno (em porcentagem);

$C=$ fator que expressa uso e manejo do solo e cultura (adimensional);

$P=$ fator que expressa a prática conservacionista do solo (adimensional).

Essa equação pode ser utilizada para "prever as perdas de solo por erosão, selecionar práticas de conservação do solo de tal forma que sejam mantidas as perdas dentro dos limites aceitáveis, determinar os declives máximos que podem ser cultivados sob determinados manejos e tipos de solo, e para estudos e pesquisas" (BERTONI \& LOMBARDI NETO, 1985 apud CARVALHO, 2008).

A seguir são discutidos brevemente os fatores dessa equação e como obter seus valores.

\section{Fator de erosividade da chuva ( $R$ )}

Expresso em MJ.ha ${ }^{-1} \cdot \mathrm{mm} \cdot \mathrm{ha}^{-1}$, esse fator traduz a erosão potencial, ou o poder erosivo da precipitação média anual da região. Determinado por meio de registros pluviográficos, $\mathrm{o}$ valor do fator $\mathrm{R}$ para uma dada região é dado em termos anuais. Lombardi Neto e Moldenhauer (1980), citados por Bertoni \& Lombardi Neto (2008), desenvolveram uma expressão para a obtenção do índice médio mensal de erosão (Equação 2).

$E I=67,355 \times\left(\frac{r^{2}}{P}\right) \times 0,85$

Em que:

$r=$ precipitação média mensal (em mm);

$P=$ precipitação média anual (em $\mathrm{mm})$.

Para se obter o fator R (índice de erosão anual), deve-se somar os valores mensais da expressão mencionada acima.

\section{Fator de erodibilidade do solo $(K)$}

Expresso em MJ.ha ${ }^{-1} \cdot \mathrm{mm} \cdot \mathrm{ha}^{-1}$, o fator de erodibilidade do solo representa a capacidade do solo de sofrer erosão por uma determinada chuva. Esse fator apresenta valores tabelados que foram experimentados e desenvolvidos por anos. De acordo com Bertoni \& Lombardi Neto (2008), é muito difícil o isolamento do solo em face do efeito de outros fatores.

\section{Fator topográfico (LS)}

O comprimento de uma rampa (em metros) e o seu grau de declividade (em \%) compreendem o fator topográfico dessa equação. Bertoni (1959), citado por Bertoni \& Lombardi Neto (2008), desenvolveu uma equação desses dois fatores para o estado de São Paulo, a qual é expressa na Equação 3:

$L S=0,00984 \times C^{0,63} \times D^{1,18}$

Em que:

$C=$ comprimento da rampa (em metros);

$D=$ grau de declive (em porcentagem).

\section{Fator de uso e manejo do solo (C)}

Esse fator diz respeito à cobertura vegetal do solo, à sequência das culturas e às práticas de manejo realizadas. Seu valor é a relação esperada entre as perdas de solo de uma área cultivada e essa mesma área descoberta. Como se trata de um fator adimensional, os valores são tabelados para algumas culturas e variações de uso e manejo do solo. Por serem cíclicas, as culturas agrícolas foram divididas em períodos uniformes (preparo do solo, plantio, estabelecimento, crescimento e colheita). Cada período apresenta uma intensidade de perda. No entanto, quando se trata de carreadores, não se deve considerar esse ciclo, pois eles não se prestam ao cultivo agrícola, e sua superfície é considerada solo exposto (BERTONI \& LOMBARDI NETO, 2008).

\section{Fator da prática conservacionista $(P)$}

$O$ último fator considerado na EUPS é adimensional e refere-se à perda de solo de uma determinada área comparativamente com e sem práticas conservacionistas. Supondo que a área não apresente nenhuma prática 
conservacionista, o valor de $\mathrm{P}$ equivale a uma cultura cultivada no sistema de "plantio morro abaixo", onde a probabilidade de erosão é maior.

Detendo-se ao valor desses fatores, é possível predizer a erosão do solo, de uma maneira geral, para uma determinada área. Amorim, Silva e Pruski (2009) relatam que a EUPS apresenta a vantagem de ser um instrumento que exige um volume pequeno de informações se comparado a modelos mais complexos. Outra vantagem é a de ser uma equação bastante conhecida e estudada. Quanto à limitação, os mesmos autores afirmam que os valores obtidos são uma representação média da área, não sendo consideradas as variabilidades espacial e temporal.

\section{MATERIAIS E MÉTODOS}

\section{Área de estudo}

Foi adotada como área de estudo uma fazenda de cana-de-açúcar localizada na bacia hidrográfica do Ribeirão do Feijão, no município de Itirapina (SP). A área para estudo foi cedida pela empresa Raízen. Foram selecionados trechos de carreadores internos com inclinações aparentemente distintas (Figura 1).

O solo da área estudada é do tipo Neossolo Quartzarênico (EMBRAPA, 1981). As inclinações das parcelas selecionadas foram obtidas por meio do uso de estação total.

\section{RESULTADOS E DISCUSSÃO}

Foram realizados os cálculos de predição para perda de solos para as três inclinações dos trechos estudados, delimitados em rampas de 10 metros de extensão, nomeados como parcelas 1, 2, 3 e 4, e com as seguintes inclinações médias: P1 e P2 5\%, P3 6\% e P4 7\%. Para tal predição, foi empregada a EUPS através da Equação 1.

Foram calculados os valores mensais do período de 2001 a 2011 (adotando os valores históricos da Estação Climatológica do Centro de Recursos Hídricos e Estudos Ambientais - CRHEA), chegando-se aos resultados apresentados na Tabela 1.

Calculando-se a média desses valores por meio de planilha eletrônica, obteve-se o valor final de $\mathrm{R}$ igual a 7.301.

$\mathrm{K}$ - fator de erodibilidade do solo, em t.ha ${ }^{-1}\left(\mathrm{MJ}^{\mathrm{h}} \mathrm{ha}^{-1} \cdot \mathrm{mm}^{-1} \cdot \mathrm{h}^{-1}\right)$ : foi adotado o valor igual a 0,0296 citado por Fujihara (2002). O tipo de solo considerado para essa equação é o Neossolo Quartzarênico.

LS - fatores topográficos que expressam o comprimento (em metros) e a declividade do terreno (porcentagem): para a obtenção do fator LS, foi utilizada a Equação 3, desenvolvida por Bertoni (1959) e citada por Bertoni \& Lombardi Neto (2008):

$L S=0,00984 \times C^{0,63} \times D^{1,18}$

Em que:

$C=$ comprimento do declive (em metros);

$D=$ grau do declive (em porcentagem).

Considerando que as rampas apresentavam 10 metros de extensão e que as declividades medidas foram de $5 \%$ (para as parcelas 1 e 2), $6 \%$ (para a 3) e 7\% (para a 4), os valores de LS obtidos foram:

- $\quad$ Para declividade de $5 \%$ - LS = 0,2804;

- $\quad$ Para declividade de $6 \%$ LS = 0,3477;

- $\quad$ Para declividade de $7 \%-$ LS = 0,4170;

Tabela 1 - Valores de R para o período de 2001 a 2011 para o local de estudo.

\begin{tabular}{c|c|c|c|c|c} 
Ano & Valor de R & Ano & Valor de R & Ano & Valor de R \\
\hline 2001 & $7.268,6$ & 2005 & $7.048,6$ & 2009 & $7.337,5$ \\
\hline 2002 & $6.955,2$ & 2006 & $6.040,8$ & 2010 & $7.571,7$ \\
\hline 2003 & $6.543,6$ & 2007 & $8.119,2$ & 2011 & $8.596,1$ \\
\hline 2004 & $7.881,5$ & 2008 & $6.924,8$ & - & - \\
\hline
\end{tabular}

Fonte: Estação Climatológica do Centro de Recursos Hídricos e Estudos Ambientais (2012)

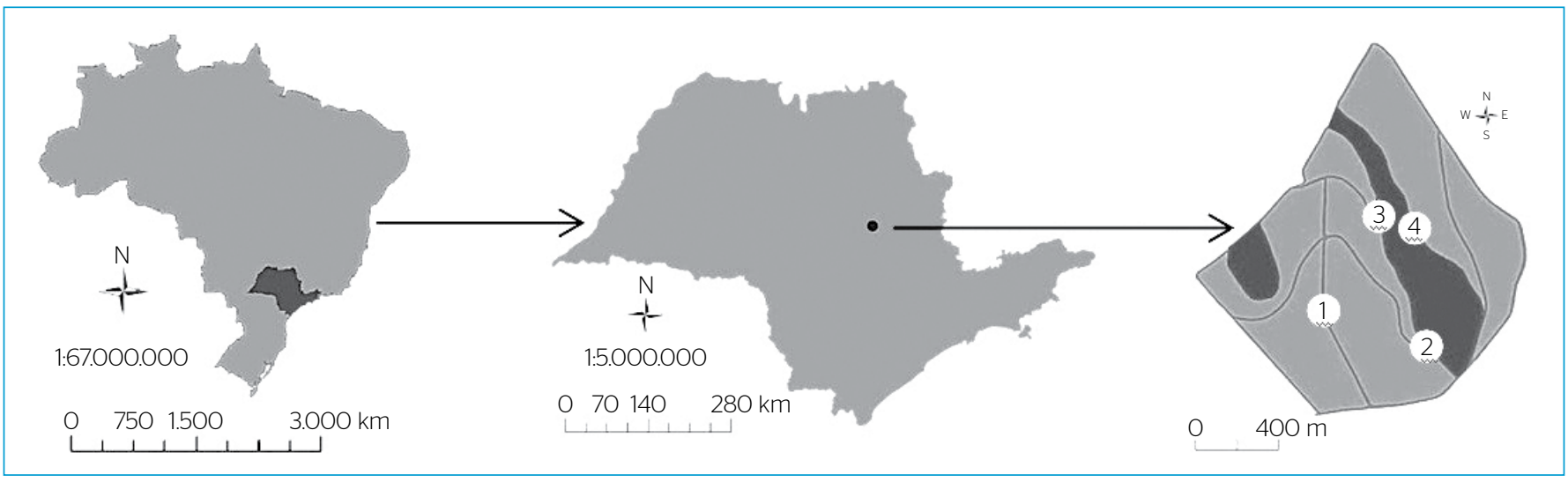

Figura 1 - Área de estudo, com destaque para o estado de São Paulo, a região de estudo dentro do estado e a Fazenda Santo Antônio do Lobo, com os quatro trechos selecionados (parcelas) nos carreadores. 
- C - fator que expressa uso e manejo do solo e cultura: como o carreador serve a cultura para escoamento de sua produção, sua função é manter-se livre de cobertura vegetal e sem impedimentos físicos que dificultem o trânsito por ele. Portanto, o valor de C para os carreadores deve ser considerado como solo exposto (VÁZQUEZ-FERNÁNDEZ et al., 1996), apresentando assim o valor adimensional de 1,0 ;

- $\mathrm{P}$ - fator que expressa a prática conservacionista do solo (BERTONI \& LOMBARDI NETO, 2008), conforme apresentado na Tabela 2.

Embora os carreadores estejam em um local onde o cultivo se dá em contorno, estes não recebem nenhum tratamento conservacionista, com exceção do nivelamento (realizado com motoniveladora) às vésperas da colheita. Por esse motivo, decidiu-se pela adoção do valor referente ao plantio morro abaixo, correspondente a 1,0.

A predição de perda de solo por unidade de área e tempo, para a inclinação de $5 \%$ (representando as parcelas 1 e 2), corresponde a 60,6 t.ha ${ }^{-1}$.ano ${ }^{-1}$ e foi determinada com base na Equação 4 :

$A=7.301 \times 0,0296 \times 0,2804 \times 1,0 \times 1,0=60,6$

A predição de perda de solo por unidade de área e tempo, para a inclinação de $6 \%$ (representando a parcela 3 ), corresponde a 75,1 t.ha ${ }^{-1}$.ano ${ }^{-1}$ e foi determinada pela Equação 5:

$A=7.301 \times 0,0296 \times 0,3477 \times 1,0 \times 1,0=75,1$

Tabela 2 - Valor de P para emprego na Equação Universal de Perda de Solo, de acordo com algumas práticas conservacionistas.

\begin{tabular}{l|c} 
Práticas conservacionistas & Valor de P \\
\hline Plantio morro abaixo & 1,0 \\
\hline Plantio em contorno & 0,5 \\
\hline Alternância de campinas + plantio em contorno & 0,4 \\
\hline Cordões de vegetação permanente & 0,2
\end{tabular}

Fonte: Bertoni e Lombardi Neto (2008).
A predição de perda de solo por unidade de área e tempo, para a inclinação de 7\% (representando a parcela 4), corresponde a 90,1 t.ha-1 ano $^{-1}$ e foi determinada por meio da Equação 6:

$A=7.301 \times 0,0296 \times 0,417 \times 1,0 \times 1,0=90,1$

Portanto, como evidenciam os cálculos através da EUPS, há uma alta produção quantitativa de sedimentos para essas características específicas de tipo de solo, inclinações e práticas de uso e manejo. Essas taxas de perdas de solo parecem pouco expressivas diante de dados apresentados por Telles (1999), que estima uma perda de 175 t.ha ${ }^{-1}$.ano-1 para estradas periurbana, ou por Toy (1982), citado por Simões \& Coiado (2003), no qual é apresentado um limite de perdas de solo de 338 t.ha ${ }^{-1}$.ano ${ }^{-1}$ para construção de estradas. No entanto, encontram-se muito acima das perdas médias estimadas para o estado de São Paulo, de 19 t.ha ${ }^{-1}$.ano-1 (ALMEIDA, 1981 apud PRUSKI, 2009), e também para a tolerância média de perdas de solo para o Neossolo Quartzarênico, de 6,8 t.ha ${ }^{-1}$.ano ${ }^{-1}$, conforme Fujihara (2002). $\mathrm{O}$ resultado desses valores também é superior à predição em áreas agricultadas com a cana-de-açúcar, de acordo com Martinelli \& Filoso (2007), os quais obtiveram uma estimativa superior a 30 t.ha $^{-1} \cdot$ ano $^{-1}$, e Sparovek \& Schnug (2001), para os quais o valor calculado foi de 31 t.ha $^{-1}$. no $^{-1}$.

\section{CONCLUSÃO}

De acordo com o emprego da EUPS, pôde-se constatar a predição de perdas de solo variando (para inclinações de 5 a 7\%) de 60,6 t.ha- ${ }^{-1} \cdot$ ano $^{-1}$ a 90,1 t.ha $\mathbf{~}^{-1}$.ano ${ }^{-1}$, considerando ainda o Neossolo Quartzarênico como solo local da área de estudo. Essa ferramenta se mostrou de fácil aplicabilidade, podendo ser empregada a outras localidades e diferentes tipos de solo de maneira que se forme um banco de dados sobre a erosão em carreadores de cana.

Tal estimativa demonstra a necessidade de atenção que os carreadores de cana-de-açúcar devem receber tanto por sua produção quantitativa de sedimentos, quanto por sua importância dentro da cadeia produtiva agroindustrial.

\section{REFERÊNCIAS}

ALMEIDA, J.R. (1981) Erosão dos solos e suas consequências. Informe Agropecuário, v. 7, n. 80, p. 17-26.

AMORIM, R.S.S.; SILVA, D.D.; PRUSKI, F.F. (2009) Principais modelos para estimar solos em áreas agrícolas. In: PRUSKI, F.F. (org.). Conservação do solo e água: práticas mecânicas para o controle da erosão hídrica. Viçosa: Editora da UFV. p. 74-107.

BARRETO, A.G.O.P.; LINO, J.S.; SPAROVEK, G. (2009) Bibliometria da pesquisa brasileira em erosão acelerada do solo: instituições, temas, espaço e cronologia. Revista Brasileira de Ciência do Solo, Viçosa, v. 33, n. 6, p. 1845-1854. Disponível em: <http://dx.doi.org/101590/ S0100-06832009000600033>. Acesso em: 28 fev. 2014.

BERTONI, J. (1959) O espaçamento de terraços em culturas anuais, determinado em função das perdas por erosão. Bragantia, Campinas, v. 18, p. 113-140. http://dx.doi.org/10.1590/S0006-87051959000100010

BERTONI, J.; LOMBARDI NETO, F. (1985) Conservação do solo. Piracicaba: Livroceres. 392 p. 
BERTONI, J.; LOMBARDI NETO, F. (2008) Conservação do solo. 6. ed. São Paulo: Ícone.

CARVALHO, N.O. (2008) Hidrossedimentologia prática. 2. ed. Rio de Janeiro: Interciência.

EMPRESA BRASILEIRA DE PESQUISA AGROPECUÁRIA (EMBRAPA). (1981) Secretaria da Agricultura e Abastecimento do Estado de São Paulo. Levantamento pedológico semi-detalhado do Estado de São Paulo: quadrícula de São Carlos. Escala 1:100.000. São Paulo: EMBRAPA.

FENDRICH, R; OBLADE, N.L; AISSE, M.M; GARCIA, C.M. (1997) Drenagem e controle da erosão urbana. 4. ed. Curitiba: Champagnat. 486 p.

FUJIHARA, A.K. (2002) Predição de erosão e capacidade de uso do solo numa microbacia do oeste paulista com suporte de geoprocessamento. 111 f. Dissertação (Mestrado) - Escola de Superior de Agricultura “Luiz de Queiroz”, Universidade de São Paulo, Piracicaba.

GALETI, P.A. (1987) Práticas de controle à erosão. Campinas: Instituto Campineiro de Ensino Agrícola. 278 p.

LOMBARDI NETO, F.; DRUGOWICH, M.I. (coords.). (1994a) Manual técnico de manejo e conservação de solo e água. São Paulo: CATI, 1994a. (Manual técnico, n. 41).

LOMBARDI NETO, F.; DRUGOWICH, M.I. (coords.). (1994b) Manual técnico de manejo e conservação de solo e água. São Paulo: CATI. (Manual técnico, n. 42).

LOMBARDI NETO, F;; MOLDENHAUER, W.C. (1980) Erosividade da chuva: sua distribuição e relação com perdas de solo em Campinas, SP. In: ENCONTRO NACIONAL DE PESQUISA SOBRE CONSERVAÇÃO DO SOLO, 3., 1980, Recife. Anais... Recife. 13 p.

MARTINELLI, L.A.; FILOSO, S. (2007) Polluting effects of Brazil's sugar-ethanol industry. Nature, v. 445, n. 364. Disponível em: <http:// www.nature.com/nature/journal/v445/n7126/full/445364c.html>. Acesso em: 22 fev. 2014. https://doi.org/10.1038/445364c
PRUSKI, F.F. (org.). (2009) Conservação do solo e água: práticas mecânicas para o controle da erosão hídrica. Viçosa: Editora da UFV.

RIGHETTO, A.M. (1998) Hidrologia e recursos hídricos. São Carlos: EESC/USP.

SCARPINELLA, G.D.A. (2012) Erosão em carreadores da cultura da cana-de-açúcar: estudo de caso na bacia do Ribeirão do Feijão (SP). 209f. Tese (Doutorado) - Escola de Engenharia de São Carlos, Universidade de São Paulo, São Carlos.

SIMÕES, S.J.G.; COIADO, E.M. (2003) Processos erosivos. In: PAIVA, J.B.D.; PAIVA, E.M.C.D. Hidrologia aplicada à gestão de pequenas bacias hidrográficas. São Paulo: ABRH. cap. 10.

SPAROVEK, G.; SCHNUG, E. (2001) Temporal Erosion-induced soil degradationand yield loss. Soil Science Society of American Journal, v. 65, n. 5, p. 1479-1486. http://doi.org/10.2136/sssaj2001.6551479x

TELLES, D.D.A. (1999) Água na Agricultura e Pecuária. In: REBOUÇAS, A.C.; BRAGA, B. \& TUNDISI, J.G. Águas doces no Brasil: capital ecológico, uso e conservação. São Paulo: Academia Brasileira de Ciências/IEA-USP. p. 305-338.

TOY, J.J. (1982) Accelerated erosion: process, problems, and prognosis. Geology, v. 10, n. 10, p. 524-529. https://doi. org/10.1130/0091-7613(1982)10\%3C524:AEPPAP\%3E2.0.CO;2

VAZZQUEZ-FERNÁNDEZ, G.A.; FORMAGGIO, A.R.; EPIPHANIO, J.C.N.; GLERIANI, J.M. (1996) Determinação de sequências culturais em microbacia hidrográfica para caracterização do fator $C$ da EUPS, utilizando fotografia aérea. In: SIMPÓSIO BRASILEIRO DE SENSORIAMENTO REMOTO, 8., 1996, Salvador. Anais... São Paulo: INPE. p. 63-67.

WISCHMEIER, W.H.; SMITH, D.D. (1978) Predicting rainfall erosion Iosses: a guide to conservation planning. U.S. Department of Agriculture. (n. 537) 